Article

\title{
Improving the W Coating Uniformity by a COMSOL Model-Based CVD Parameter Study for Denser $\mathrm{W}_{f} / \mathrm{W}$ Composites
}

\author{
Leonard Raumann 1,2*(D), Jan Willem Coenen ${ }^{1,3} \mathbb{D}$, Johann Riesch ${ }^{4}$, Yiran Mao ${ }^{1}$, Daniel Schwalenberg ${ }^{1}$, \\ Hanns Gietl ${ }^{5}$, Christian Linsmeier ${ }^{1}$ (D) and Olivier Guillon ${ }^{1,2,6}$
}

1 Forschungszentrum Jülich GmbH (Partner in the Trilateral Euregio Cluster), Institute for Energy and Climate Research, 52428 Jülich, Germany; j.w.coenen@fz-juelich.de (J.W.C.); y.mao@fz-juelich.de (Y.M.); d.schwalenberg@fz-juelich.de (D.S.); Ch.Linsmeier@fz-juelich.de (C.L.); o.guillon@fz-juelich.de (O.G.)

2 Institute of Mineral Engineering, Rheinisch-Westfälische Technische Hochschule Aachen, 52062 Aachen, Germany

3 Department of Engineering Physics, University of Wisconsin-Madison, Madison, WI 53706, USA

4 Max-Planck-Institute for Plasma Physics, 85748 Bavaria, Germany; johann.riesch@ipp.mpg.de

5 Oak Ridge National Laboratory, Oak Ridge, TN 37830, USA; gietlha@ornl.gov

6 JARA-Energy, Jülich Aachen Research Alliance, 52428 Jülich, Germany

* Correspondence: 1.raumann@fz-juelich.de

check for updates

Citation: Raumann, L.; Coenen, J.W.; Riesch, J.; Mao, Y.; Schwalenberg, D.; Gietl, H.; Linsmeier, C.; Guillon, O. Improving the W Coating Uniformity by a COMSOL Model-Based CVD Parameter Study for Denser $\mathrm{W}_{f} / \mathrm{W}$ Composites. Metals 2021, 11, 1089. https://doi.org/10.3390/met11071089

Academic Editor: Leszek Adam Dobrzanski

Received: 26 May 2021

Accepted: 3 July 2021

Published: 8 July 2021

Publisher's Note: MDPI stays neutral with regard to jurisdictional claims in published maps and institutional affiliations.

Copyright: (C) 2021 by the authors Licensee MDPI, Basel, Switzerland. This article is an open access article distributed under the terms and conditions of the Creative Commons Attribution (CC BY) license (https:/ / creativecommons.org/licenses/by/ $4.0 /)$.

\begin{abstract}
Tungsten (W) has the unique combination of excellent thermal properties, low sputter yield, low hydrogen retention, and acceptable activation. Therefore, $\mathrm{W}$ is presently the main candidate for the first wall and armor material for future fusion devices. However, its intrinsic brittleness and its embrittlement during operation bears the risk of a sudden and catastrophic component failure. As a countermeasure, tungsten fiber-reinforced tungsten $\left(\mathrm{W}_{f} / \mathrm{W}\right)$ composites exhibiting extrinsic toughening are being developed. A possible $\mathrm{W}_{f} / \mathrm{W}$ production route is chemical vapor deposition (CVD) by reducing $\mathrm{WF}_{6}$ with $\mathrm{H}_{2}$ on heated $\mathrm{W}$ fabrics. The challenge here is that the growing CVD-W can seal gaseous domains leading to strength reducing pores. In previous work, CVD models for $\mathrm{W}_{f} / \mathrm{W}$ synthesis were developed with COMSOL Multiphysics and validated experimentally. In the present article, these models were applied to conduct a parameter study to optimize the coating uniformity, the relative density, the $\mathrm{WF}_{6}$ demand, and the process time. A low temperature and a low total pressure increase the process time, but in return lead to very uniform $\mathrm{W}$ layers at the micro and macro scales and thus to an optimized relative density of the $\mathrm{W}_{f} / \mathrm{W}$ composite. High $\mathrm{H}_{2}$ and low $\mathrm{WF}_{6}$ gas flow rates lead to a slightly shorter process time and an improved coating uniformity as long as $\mathrm{WF}_{6}$ is not depleted, which can be avoided by applying the presented reactor model.
\end{abstract}

Keywords: tungsten; fiber composite; chemical vapor deposition; modeling; parameter study

\section{Introduction}

To realize commercial fusion power plants, the development of high-performance materials with adequate lifetimes is essential. One of the ultimate reactor-design challenges is to deal with the enormous heat and particle fluxes, plasma erosion, neutron irradiation, and transmutation [1-4]. Tungsten (W) is currently the main candidate material as it meets most of these requirements [5,6]. Tungsten has a high thermal conductivity, the highest melting point of all metals $(3695 \mathrm{~K})$ and a high resistance against plasma erosion. The reason for these properties is the combination of a high atomic number $(z=74)$ and a high atomic binding energy (approximately $11.8 \mathrm{eV}$ [7]), which is, e.g., approximately 4.6 times the binding energy of lead $(\mathrm{Pb})$ [8]. However, tungsten has the drawback of a high ductile-tobrittle transition temperature (DBTT), which ranges from 300-1200 K, depending on the fabrication process and treatment $[9,10]$. Furthermore, the DBTT is suspected to increase by several hundred Kelvin due to neutron irradiation within a year of fusion operation [11,12]. 
Studies have shown that thermal stresses induced by transient events during plasma instabilities can lead to the failure of complete plasma facing components consisting of W sheet material [13]. This is especially problematic for smaller reactor designs, which have even higher material requirements. New materials are being developed to overcome this issue [14]. One of these new materials is a tungsten fiber-reinforced tungsten $\left(\mathrm{W}_{f} / \mathrm{W}\right)$ composite similar to fiber-reinforced ceramics [12,14-19]. Due to the increased toughness and damage resistance below the DBTT [20], $\mathrm{W}_{f} / \mathrm{W}$ is expected to provide longer lifetimes compared to pure $\mathrm{W}$. The main benefit here is the extrinsic toughening mechanisms in contrast to only intrinsic ones [21]. It is expected that $\mathrm{W}_{f} / \mathrm{W}$ can endure irradiation embrittlement better than conventional materials [11].

To produce $W_{f} / W$, potassium doped drawn $W$ fibers are used. The potassium doping acts to suppress recrystallization and thus allows the extrinsic toughening and ductile deformation of fibers even beyond the pure tungsten recrystallization temperature. Details of this can be found in $[19,22]$. To obtain pseudo-ductility despite of a brittle matrix, energy dissipating mechanisms needs to be enabled [23]. This can be achieved by tailoring a fiber-matrix-interface to have a slightly lower fracture energy than the $\mathrm{W}$ fibers. Therefore, as the first step, the $W$ fibers are coated by a thin layer of $\mathrm{Y}_{2} \mathrm{O}_{3}[21,24]$. Currently, physical vapor deposition is used for this.

In the next step, the coated fibers are embedded in the $W$ matrix. In addition to powder metallurgy utilizing 1.5-2.5 mm short fibers [25-27], a possible synthesis route is chemical vapor deposition (CVD) on several $\mathrm{cm}$ long fibers or textile pre-forms [28,29]. For this work, CVD was used with tungsten hexafluoride $\left(\mathrm{WF}_{6}\right)$ and hydrogen $\left(\mathrm{H}_{2}\right)$ as gaseous precursors. They react on surfaces heated above $550 \mathrm{~K}$ to solidify $\mathrm{W}$ with high purity [30] and gaseous hydrofluoric acid, as described by Equation (1).

$$
\mathrm{WF}_{6}(\mathrm{~g})+3 \mathrm{H}_{2}(\mathrm{~g}) \longrightarrow \mathrm{W}(\mathrm{s})+6 \mathrm{HF}(\mathrm{g})
$$

A picture of a possible experimental setup to produce $W_{f} / W$ layer-wise is shown in Figure 1. The CVD substrate (a W fabric) is placed onto a heating table below a gas shower supplying the CVD precursors. During the deposition process, this setup is located inside of a bell-shaped vessel, to which the gas inlets, the vacuum pumps, and the exhaust gas handling are connected. After a fabric is coated, the process is stopped and the next fabric layer is placed onto the previous one, and so forth. A detailed description of the $W_{f} / W$ production can be found in [31,32].

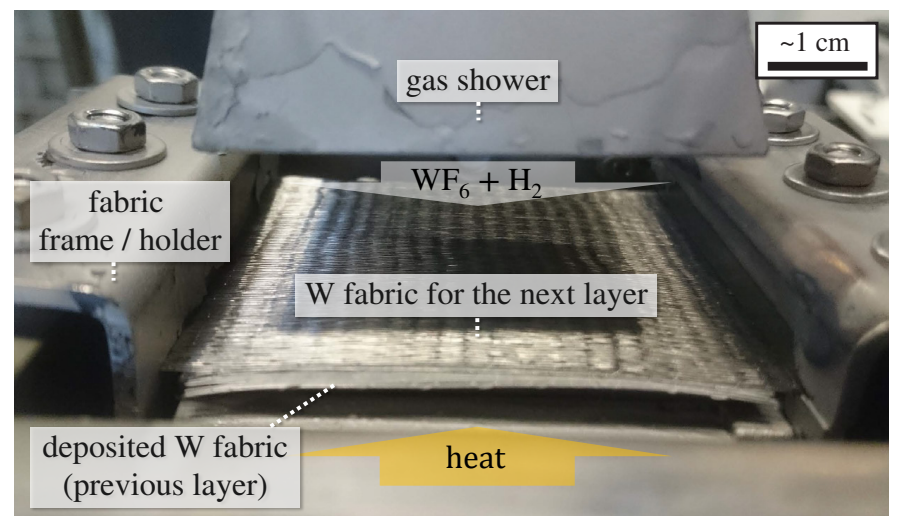

Figure 1. Picture of a $\mathrm{W}_{f} / \mathrm{W}$ production step: a fabric mounted on a previously coated fabric layer grown on the heating table inside of the CVD chamber.

One of the major process challenges is that pores can remain in the composite if the solid W matrix growing from adjacent fibers connects and seals off gaseous domains from the precursor supply. These pores in the $\mathrm{W}$ matrix between the fibers weaken the mechanical properties of the composite as they lead to stress concentrations, which can 
lead to premature matrix crack initiation and thus delamination of coated layers [33], as happened in the tensile specimen shown in Figure 2.

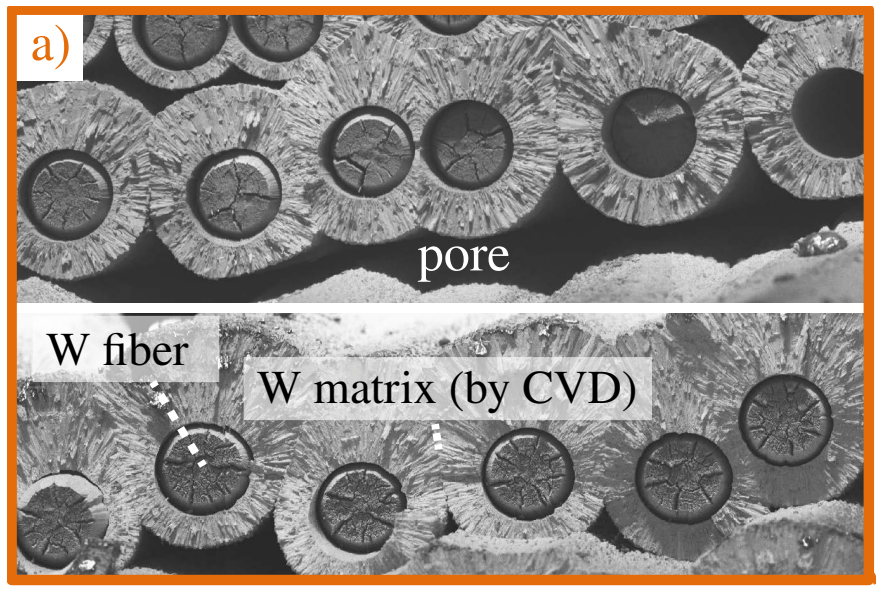

Tensile test sample

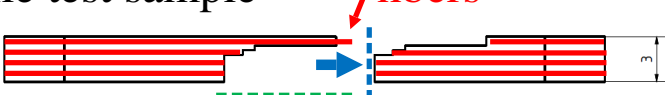

c) 1 b)

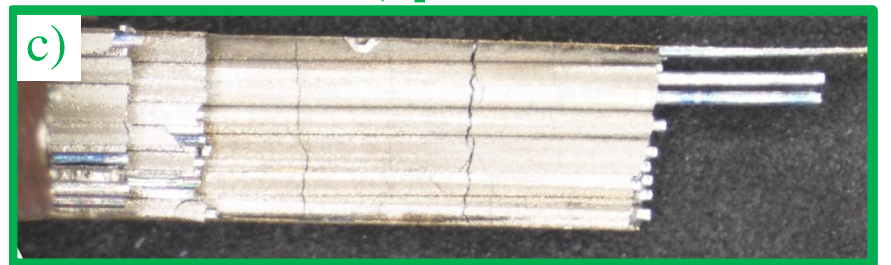

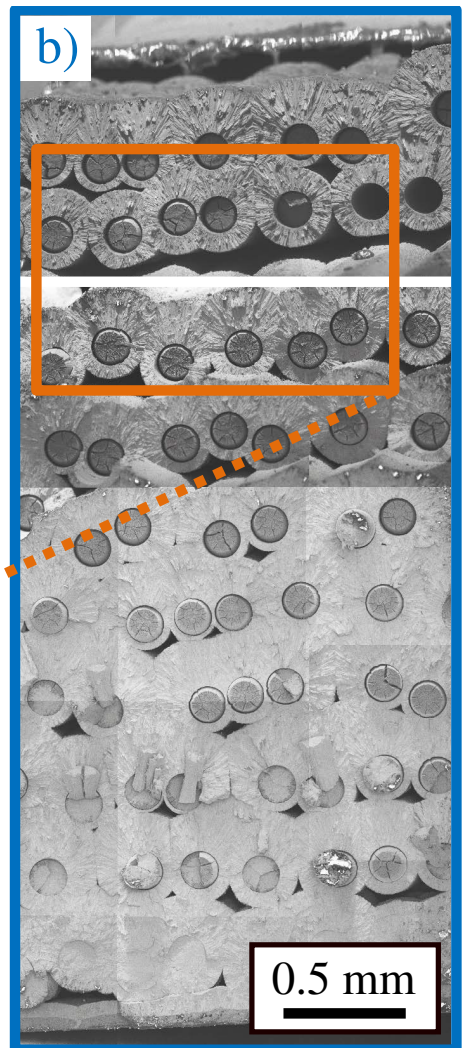

Figure 2. Fracture surface of a $\mathrm{W}_{f} / \mathrm{W}$ tensile test specimen delaminated due to large pores, with (a) being a close-up of (b), with (b) being a SEM image perpendicular to the warp fiber axes, and with (c) being a photo perpendicular to a delaminated layer. The viewing angles are sketched in the center. Details can be found in [33].

The porosity can be reduced by increasing the distance between the fibers; however, a lower fiber volume fraction leads again to a lower fiber-reinforcing effect and thus to lower fracture toughness [34]. Therefore, the current work was motivated by the question regarding whether the porosity in $\mathrm{W}_{f} / \mathrm{W}$ can also be reduced by only optimizing the CVD process parameters (temperature, gas flow rates and pressure) without reducing the fiber volume fraction. To answer this question, CVD models were developed utilizing the commercial Finite Element Method (FEM) software COMSOL Multiphysics [35].

The first development step focused on the influence of the CVD process parameters on the $\mathrm{W}$ deposition rate, as presented in $[36,37]$.

The second step concentrated on the application of the $\mathrm{W}$ deposition rate equations to model and experimentally validate the $\mathrm{W}_{f} / \mathrm{W}$ synthesis at the macro- and micro-scales. The scales were modeled and linked via the boundary conditions regarding precursor concentrations and temperature. For a single CVD process parameter set, the coatings within more than 50 fiber gaps were studied in high detail. The fibers varied in their positions and distances and were exposed to spatially varying precursor concentrations (due to precursor consumption). The inner coatings and pore sizes matched very well between experiment and simulation [31,37].

In this article, the macro- and micro-scale models are applied to conduct CVD parameter studies, whereby the fiber positions are kept constant. The micro-scale model is used to study the local effects of the physical parameters (precursor partial pressures and surface temperature). The macro-scale reactor model is applied to study the effects of the CVD process parameters (gas inlet flow rates, total pressure, and heater temperature). 
The goal is to optimize the local physical parameters regarding the precursor infiltration, inner coating uniformity, and relative density $\left(\rho_{\text {rel }}\right)$, as well as to optimize the CVD process parameters regarding advantageous local physical parameters, coating uniformity along the whole sample, the $\mathrm{WF}_{6}$ demand, and the process time.

\section{Model Descriptions}

2.1. Micro-Scale Model

\subsubsection{Geometry and Boundary Conditions}

The geometric shape of the micro-scale model is based on the gaseous area around two adjacent $\mathrm{W}$ fibers and the heated surface, on which the first fabric layer is placed during $\mathrm{W}_{f} / \mathrm{W}$ production. Figure 3 a shows a small section of the fabric. The weft fibers cause the warp fibers to undulate as shown in Figure $3 \mathrm{~b}$. Since adjacent weft fibers have a relatively large distance of about $3 \mathrm{~mm}$, the model was simplified to a 2D model with the boundaries shown in Figure 3c. A small warp fiber distance was chosen in order to investigate a scenario, where precursor infiltration and consumption play a major role, so that the parameter studies will provide clearer trends.
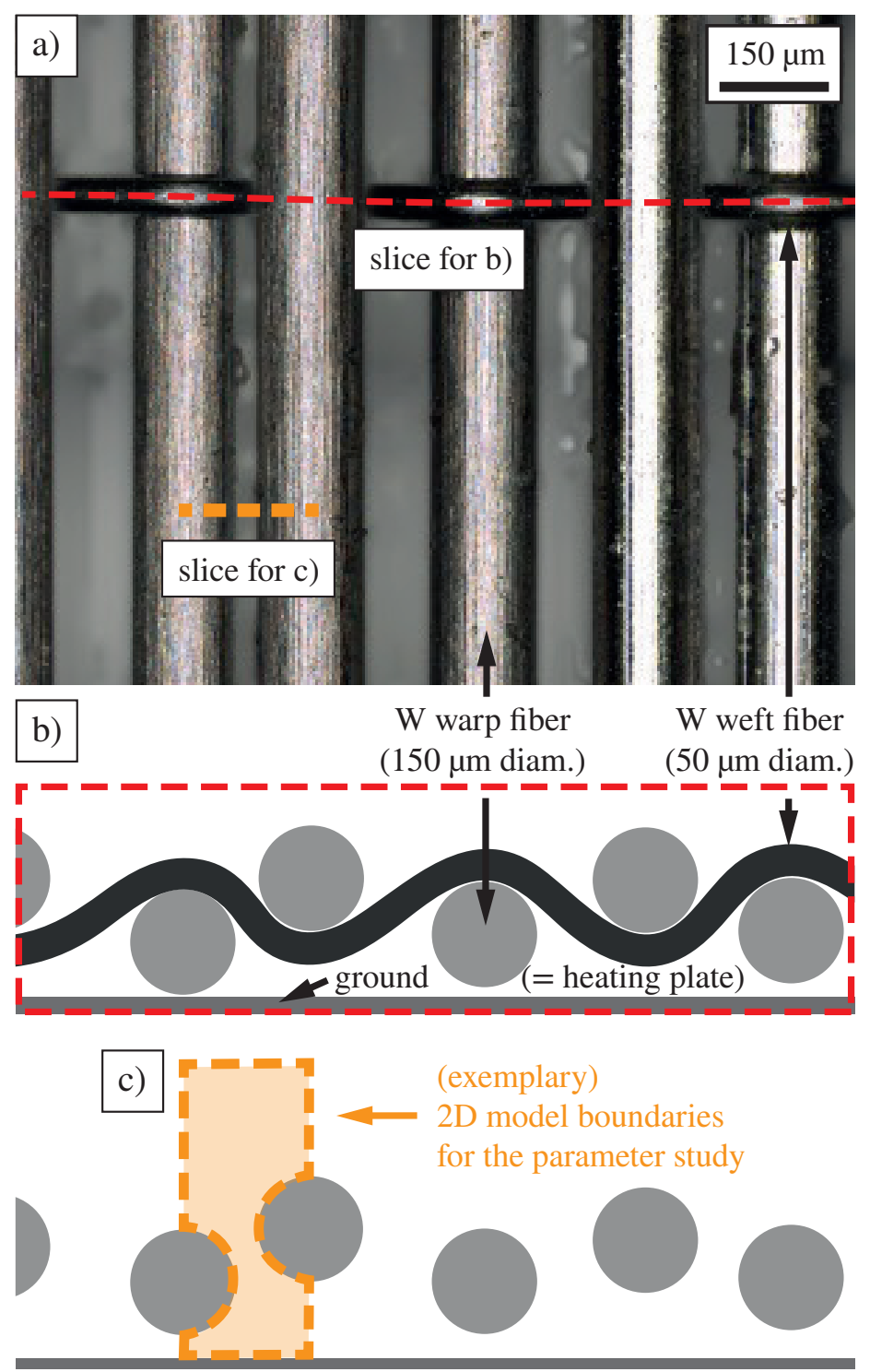

Figure 3. (a) Close-up of an uncoated $W$ fabric showing a weft and several warp fibers. (b,c) Sketches for cross-sectional slices perpendicular to the warp fiber axes. The micro-scale model boundary was added to (c). 
Geometry and transport boundaries are shown in Figure 4a. Based on experimentally validated results $[31,37]$, the temperature $(T)$ was set to be spatially constant and the gas volume flow speed was set to zero in this micro scale. Earlier results [31,37] also showed that the major transport mechanism of the gaseous species is driven by vertical diffusion. Therefore, the top-boundary was set to a constant partial pressure (green line) functioning as source for $\mathrm{WF}_{6}$ and $\mathrm{H}_{2}$ and as a sink for HF. The side boundaries were set to "no species flux" (red lines). The blue lines represent the solid W reaction surfaces of the fibers and the ground. Here, the species mass fluxes towards $\left(\mathrm{WF}_{6}, \mathrm{H}_{2}\right)$ and from $(\mathrm{HF})$ the surfaces were calculated via the stoichiometry, resulting from Equation (1), in conjunction with the W deposition rate $\left(R_{\mathrm{W}}\right.$, Equation (2), experimentally validated in [36]).

a) Species transport

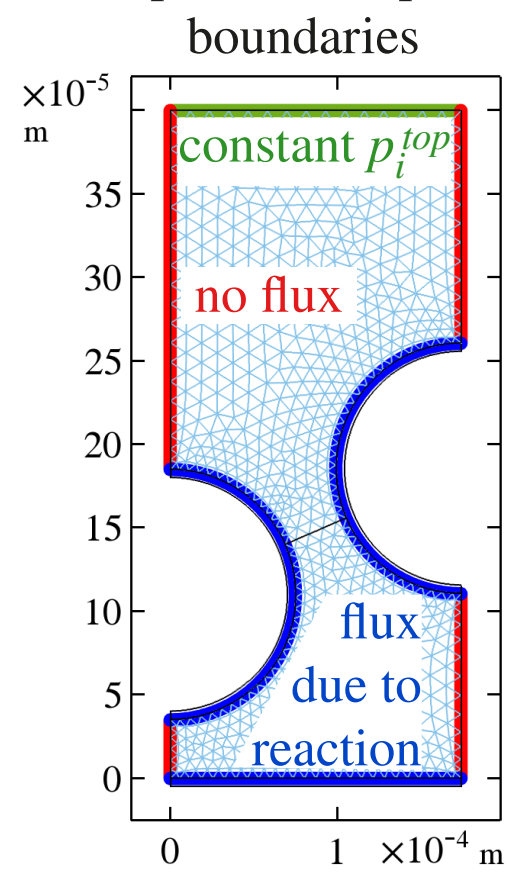

b) Pseudo time steps

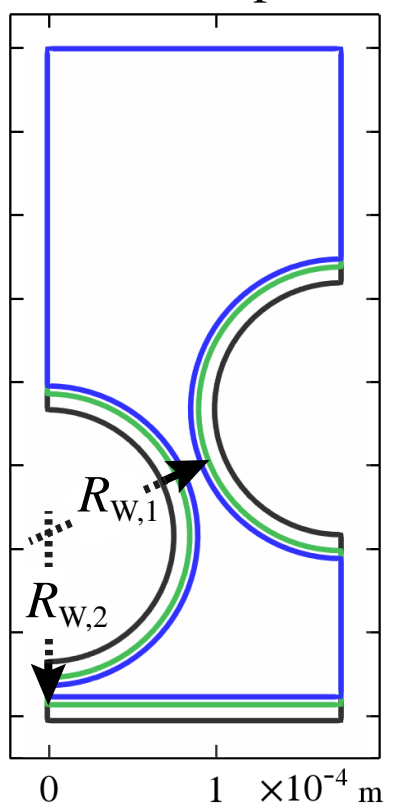

c) Study concept

$\begin{aligned} \text { if } & R_{\mathrm{W}, 2} / R_{\mathrm{W}, 1}=1: \\ \rightarrow & \text { uniform } \\ & \text { growth } \\ \rightarrow & \text { best relative } \\ & \text { density } \\ \text { if } & R_{\mathrm{W}, 2} / R_{\mathrm{W}, 1} \ll 1: \\ \rightarrow & \text { pore entrance } \\ & \text { closes too fast } \\ \rightarrow & \text { large pore }\end{aligned}$

Figure 4. Setup and concept for the parameter study regarding the infiltration of a single symmetric pore adjacent to two W fibers. (a) Micro-scale model boundaries for species transport. (b) Visualization of three different geometries (pseudo time steps) of the stationary $\mathrm{W}$ infiltration simulation resulting in (shrinking) pore entrance sizes of 39.8, g20.9, and b11.4 $\mu \mathrm{m}$. The positions of $R_{\mathrm{W}, 1}$ and $R_{\mathrm{W}, 2}$ are also shown. The quotient $\left(R_{\mathrm{W}, 2}\right.$ divided by $\left.R_{\mathrm{W}, 1}\right)$ is used as an evaluation quantity for the coating uniformity. The meaning of the possible results for this evaluation quantity is summarized in (c), the study concept.

To account for gas-to-wall interactions, Knudsen diffusion was combined with a mixture-averaged ordinary diffusion as in previous work [31] (Section 3.2.4). As CVD-W grows, the pore entrance becomes smaller, making Knudsen diffusion more relevant. To investigate such transient effects in stationary simulations, the inputs for the fiber radius and the ground surface height were varied. The different starting geometries are shown as different colors in Figure $4 \mathrm{~b}$. They can be seen as pseudo time steps in the order black to ggreen to bblue.

$$
R_{\mathrm{W}}=\min \left(R_{\mathrm{WF}_{6} \text { indep. }}, R_{\mathrm{WF}_{6} \text { dep. }}\right)
$$

with $R_{\mathrm{W}}=\mathrm{W}$ deposition rate $(\mathrm{nm} / \mathrm{s}), R_{\mathrm{WF}_{6}}$ dep. $=R_{\mathrm{W}}$ being dependent of the $\mathrm{WF}_{6}$ partial pressure

$$
R_{\mathrm{WF}_{6} \text { dep. }}=\left(\frac{1}{k_{1} p_{\mathrm{WF}_{6}}}+\frac{1}{k_{2} \exp \left(\frac{-E_{A}}{R T}\right)\left[p_{\mathrm{H}_{2}}\right]^{1 / 2}\left[p_{\mathrm{WF}_{6}}\right]^{1 / 6}}\right)^{-1}
$$


with $E_{A}=64 \mathrm{~kJ} / \mathrm{mol}, k_{1}=(32.63 \pm 2.88) \times 10^{-9} \mathrm{~m} \mathrm{~s}^{-1} \mathrm{~Pa}^{-1}$ and $k_{2}=(45.79 \pm 1.28)$ $\times 10^{-7} \mathrm{~m} \mathrm{~s}^{-1} \mathrm{~Pa}^{-2 / 3}[38]$.

$$
R_{\mathrm{WF}_{6} \text { indep. }}=k_{0} \exp \left(\frac{-E_{A}}{R T}\right)\left[p_{\mathrm{H}_{2}}\right]^{1 / 2}\left[p_{\mathrm{WF}_{6}}\right]^{0}
$$

with $E_{A}=(73.7 \pm 0.9) \mathrm{kJ} / \mathrm{mol}$ and $k_{0}=(38.22 \pm 4.85) \times 10^{-6} \mathrm{~m} \mathrm{~s}^{-1} \mathrm{~Pa}^{-1 / 2}$ [36]. The equations are for $\mathrm{H}_{2}: \mathrm{WF}_{6}$ ratios $\geq 3$.

To achieve fast convergence and high model robustness, $R_{\mathrm{W}}$ was smoothly lowered at a $W_{6}$ gas concentration $\leq 1 \times 10^{-5} \mathrm{~mol} / \mathrm{m}^{3}$ towards zero at $1 \times 10^{-6} \mathrm{~mol} / \mathrm{m}^{3}$. In this way, practically irrelevant deposition rates do not have to be calculated inside of the pore when $\mathrm{WF}_{6}$ is already nearly depleted.

\subsubsection{Parameter Study Concept}

As stated in the introduction, the aim is to increase the relative density $\left(\rho_{\text {rel }}\right)$ for a given infiltration substrate geometry. To fill the gas domain below the fibers completely with a $\mathrm{W}$ coating, the $\mathrm{W}$ deposition rate $\left(R_{\mathrm{W}}\right)$ would need to be much faster at the end of the pore domain compared to the entrance. However, this is not possible in the investigated setup. The reason for this is that $T$ is considered as spatially constant and that the consumption of the precursors will always lead to a more or less strong partial pressure gradient for $p_{\mathrm{H}_{2}}$ and $p_{\mathrm{WF}_{6}}$. This gradient is always decreasing $R_{\mathrm{W}}$ from the pore entrance towards the pore end. Therefore, the best achievable result is to obtain the smallest possible $R_{\mathrm{W}}$ gradient. This is important for understanding the study concept and later discussion. In other words, in this setup the CVD parameters, which lead to the most uniform pore-inner coating, will also lead to the highest possible $\rho_{\text {rel }}$. Thus, the influence of $p_{i}^{\text {top }}$ and $T$ on the quotient of $R_{\mathrm{W}}$ deep inside of the pore $\left(=R_{\mathrm{W}, 2}\right)$ and at the pore entrance $\left(=R_{\mathrm{W}, 1}\right)$ were investigated. The study concept is summarized in Figure 4c.

\subsection{Macro-Scale Model (CVD-Reactor)}

The 2D axis-symmetric geometry of the macro-scale reactor model is shown in Figure 5. The gas inlet and outlet are marked in green. The heating table, fibers, and fabric frame are treated as reaction surfaces. The temperature of the heating plate was also applied to the modeled warp fibers. More details can be found in [37] and within the COMSOL Multiphysics model files uploaded to [39].

Fluid dynamics, ordinary and thermal diffusion, and heat transfer are described in [31] (Section 3.1). The difference from the model in [31] is only that some geometric adjustments have been made to estimate a more secure lower limit for $\dot{V}_{\mathrm{WF}_{6}}^{\text {inlet }}$ for which $\mathrm{WF}_{6}$ does not deplete. In [31], the first fabric layer was modeled and thus the heated ground surface under the fabric was flat. For all subsequent layers, the coatings on the previous fabric layers become a non-planar ground surface under the next fabric layers. Therefore, the flat ground surface was changed to the shape as marked orange in Figure $5 c$, since this shape has a slightly larger reaction surface and thus leads to a slightly higher precursor consumption. Furthermore, the fabric and ground radius (along the $x$-axis in Figure 5) was set to half the diagonal of the experimental square fabric and ground (Figure 1). Finally, since the reaction surface area increases during the deposition process, the stationary modeled initial warp fiber radius was increased from its starting radius $(75 \mu \mathrm{m})$ towards $127 \mu \mathrm{m}$ to examine a time-averaged geometry and not that of the first seconds.

For the parameter study, the process parameters of the CVD device $\left(T, P_{t o t}\right.$, gas flow rates) were varied and their influence on $R_{\mathrm{W}}$ along the orange-marked line in Figure $5 c$ was investigated. 

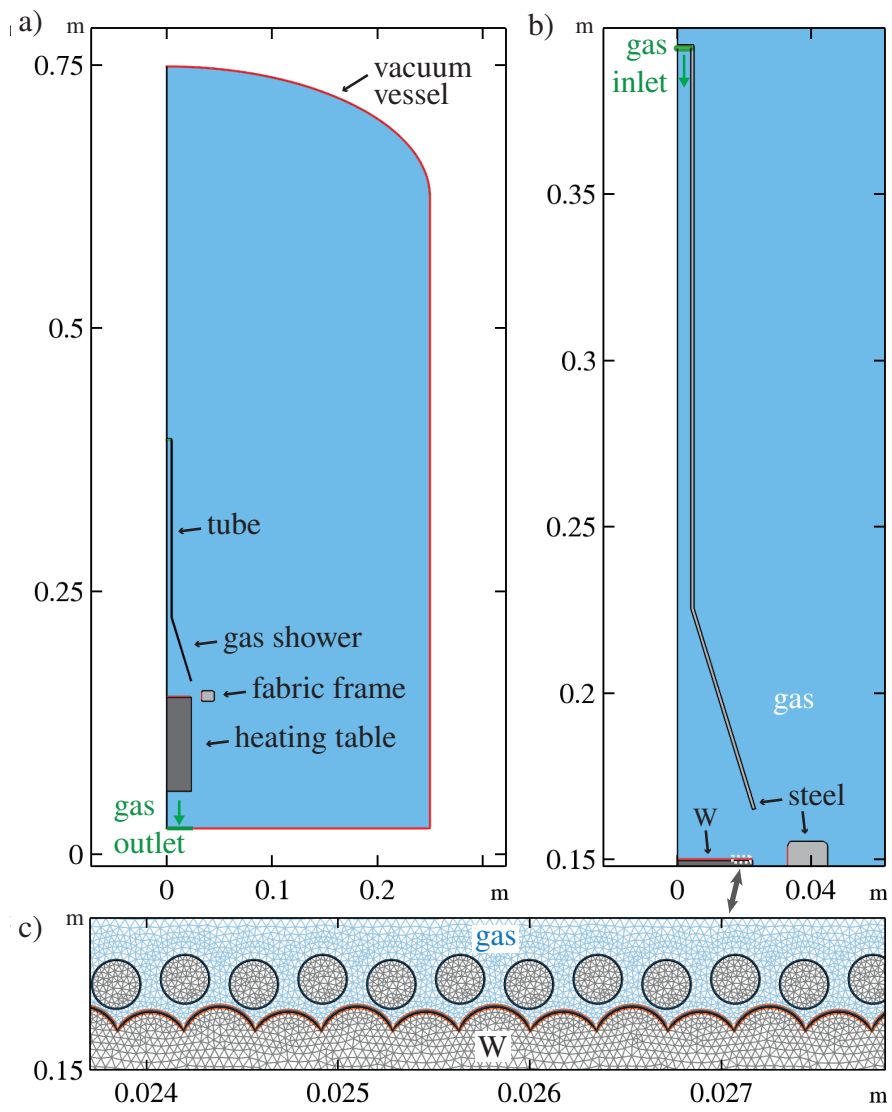

Figure 5. (a) Reactor model geometry of the CVD device with a close-up of the gas shower in (b) and with a closer look at the fibers of the new layer (floating circles) in (c). Below the fibers, the W domain is shown, which consists of the fibers from the previous layer and the CVD-W grown around these fibers (its surface is marked in orange).

Examples for flow fields and species-concentration color maps for very similar setups can be seen in previous work focusing on the model validation [31,37].

\section{Results and Discussion}

\subsection{Physical Parameter Study (Micro-Scale)}

The results of the variations in $p_{\mathrm{WF}_{6}}^{\text {top }}, p_{\mathrm{H}_{2}}^{\text {top }}$, and $T$ are shown in Figure 6 from left to right. The different starting geometries (pseudo time steps, Figure $4 \mathrm{~b}$ ) are shown as color-corresponding series (black, green, blue).

As described in the study concept (Figure $4 \mathrm{c}), y$-values $\left(R_{\mathrm{W}, 2} / R_{\mathrm{W}, 1}\right)$ near one result in a high relative density $\left(\rho_{\text {rel }}\right)$ due to a nearly uniform $\mathrm{W}$ coating and thus good pore filling. The key outcome of the parameter study is that the most uniform $\mathrm{W}$ coating can be achieved by low $T$, low $p_{\mathrm{WF}_{6}{ }^{\prime}}^{\text {top }}$ and low $p_{\mathrm{H}_{2}}^{\text {top }}$ (Figure 6). However, $p_{\mathrm{WF}_{6}}^{\text {top }}$ has a lower limit and $p_{\mathrm{H}_{2}}$ an upper limit, beyond which the coating uniformity drops significantly ( $\nabla$-symbols). The smaller the gap size between the fibers, the smaller the parameter window for avoiding these drops. The reasons for these results will be discussed in more detail in the following subsections. For an easier understanding, it is important to keep the following in mind: since $T$ is spatially constant within one simulation, each $y$-value is determined only by the effect of the varied parameters on the spatial precursor partial pressure gradients within one simulation (Equation (3)). The flatter these gradients are, the faster the precursors are transported (by diffusion) and the more slowly these precursors are consumed. 

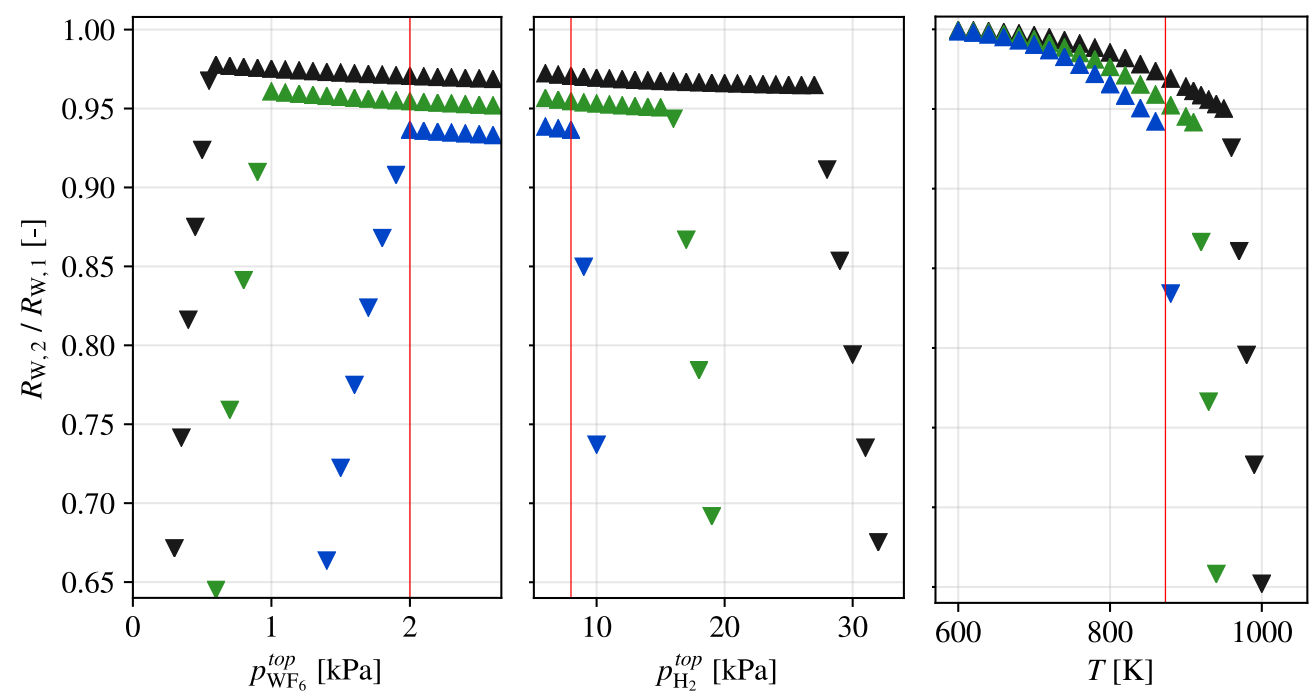

Figure 6. Parameter study results: $R_{\mathrm{W}, 2} / R_{\mathrm{W}, 1}$ (explained in Figure $4 \mathrm{~b}, \mathrm{c}$ ) vs. $p_{\mathrm{WF}_{6}}^{\text {top }} p_{\mathrm{H}_{2}}^{\text {top }}$ and $T$. The results are plotted either with a $\Delta$ or a $\nabla$ symbol, depending on whether the deposition rate deep inside the pore $\left(R_{\mathrm{W}, 2}\right)$ are independent of $p_{\mathrm{WF}_{6}}$ (Equation (4)) or dependent on $p_{\mathrm{WF}_{6}}$ (Equation (3)), respectively. The constant parameters, if not varied, were $T=873 \mathrm{~K}, p_{\mathrm{WF}_{6}}^{\text {top }}=2 \mathrm{kPa}, p_{\mathrm{H}_{2}}^{\text {top }}=8 \mathrm{kPa}$, marked as red lines, and $p_{\mathrm{HF}}^{\text {inlet }}=2 \mathrm{kPa}$. The series correspond color-wise to the different geometries, as shown in Figure $4 b$, representing the pseudo time steps.

\subsubsection{Variation of $p_{\mathrm{WF}_{6}}^{\text {top }}$}

$R_{\mathrm{W}, 1}$ and $R_{\mathrm{W}, 2}$ stay independent of $p_{\mathrm{WF}_{6}}$ (Equation (4)) as long as there is enough $\mathrm{WF}_{6}$. The corresponding simulation results are shown as $\Delta$-symbols in Figure 6. Within these $\Delta$-symbols, a slight trend can be seen. The reason for this is that a lower gas pressure leads to a faster diffusive flux $[36,40]$, and thus to flatter partial pressure gradients, and thus to a more uniform $\mathrm{W}$ coating within the pore. $\mathrm{WF}_{6}$ is the largest species in the gas mixture so its partial pressure has the biggest impact on the diffusive flux [36,40]. However, the above described trend is outweighed as soon as $p_{\mathrm{WF}_{6}}$ becomes so low that $R_{\mathrm{W}, 2}$ is limited and becomes dependent on $p_{\mathrm{WF}_{6}}$ (Equation (3)). This occurrence leads to a decrease in $R_{\mathrm{W}, 2}$ and thus can lead to a significant decrease in the coating uniformity. The corresponding data points are marked as $\nabla$-symbols. To conclude, to obtain a high coating uniformity within the pore (and thus high relative density), $p_{\mathrm{WF}_{6}}$ should be chosen low at the inlet; however, it must not become so low within the pore that it limits $R_{\mathrm{W}, 2}$.

\subsubsection{Variation of $p_{\mathrm{H}_{2}}^{\text {top }}$}

For low $p_{\mathrm{H}_{2}}$, where $R_{\mathrm{W}, 1}$ and $R_{\mathrm{W}, 2}$ are independent of $p_{\mathrm{WF}_{6}}$, two effects overlay. The first is again that a lower pressure enhances diffusion [36,41]. As $\mathrm{H}_{2}$ molecules are small, this effect is less pronounced compared to the variation of $p_{\mathrm{WF}_{6}}$. Secondly, $R_{\mathrm{W}}$ is proportional to the square root of $p_{\mathrm{H}_{2}}$ (Equation (4)). Therefore, with lower $p_{\mathrm{H}_{2}}, R_{\mathrm{W}}$ decreases and thus the $\mathrm{H}_{2}$ consumption is lowered, leading again to smaller partial pressure gradients. For very high $p_{\mathrm{H}_{2}}, R_{\mathrm{W}}$ becomes so large that $\mathrm{WF}_{6}$ becomes the limiting factor for $R_{\mathrm{W}, 2}$ again. The result is the same as for a too low $p_{\mathrm{WF}_{6}}$ : an extreme drop in uniformity. Thus, the sweet spot for the infiltration is a low $p_{\mathrm{H}_{2}}$, whereby it must be kept $\geq 3 \cdot p_{\mathrm{WF}_{6}}$ to match the reaction stoichiometry (Equation (1)) and to avoid $\mathrm{F}$ covering the reaction surface and thus hindering the adsorption and dissociation of $\mathrm{H}_{2}$ [42].

\subsubsection{Variation of $T$}

The coating inside of a pore becomes more uniform by lowering $T$ ( $y$-values go up from right to left). The reason for this is that by lowering $T, R_{\mathrm{W}}$ is strongly reduced (Equation (2)) and thus also the precursor consumption and precursor partial pressure gradients are flattened. Lowering $T$ also results in a reduced diffusive flux, which in itself 
would increase the partial pressure gradients. However, as the simulation results show, the influence of $T$ on $R_{\mathrm{W}}$ dominates. This is probably because $T$ is in the equation of the diffusion coefficient $[36,41]$ only in the base and not in the exponent, as in $R_{\mathrm{W}}$ (Arrhenius terms in Equation ((3) and (4))).

By applying a $T$ of around $673 \mathrm{~K}$, practically perfect coating uniformity can be achieved for the given infiltration geometry ( $y$-values near one). The disadvantage of lowering $T$ is obviously that the process time increases exponentially as well.

\subsubsection{Variation of the Substrate Geometry}

As the CVD-W would grow (black $\rightarrow$ green $\rightarrow$ blue, Figure $4 b$ ), the $y$-values decrease. This is again caused by the partial pressure gradients becoming steeper due to two reasons. First, the reaction surface within the pore and thus also the precursor consumption becomes larger. Second, the precursor supply is slowed down as the pore entrance becomes smaller. The reason for this is that, for a smaller pore entrance, the collisions of the gas molecules with a wall become more frequent, slowing down the diffusive flux $[43,44]$. This was implemented in the model via Knudsen diffusion [31], which is especially important for simulations at low pressures and with small gap sizes. In the shown setup, the Knudsen diffusion reduced the diffusive flux by up to a factor of 2 .

\subsection{CVD Process Parameter Study (Macro Scale)}

As stated before, a uniform pore infiltration at the micro scale is important to increase the relative density of the composite and thus its strengths and thermal conductivity. However, this is not the only criterion to improve the $\mathrm{W}_{f} / \mathrm{W}$ synthesis. Further criteria are a uniform sample coating also at the macro scale to obtain a flat composite, as well as a low $\mathrm{WF}_{6}$ demand and a short deposition duration to reduce the production costs.

\subsubsection{Variation of $T$}

In Figure $7, R_{\mathrm{W}}$ is plotted vs. the heating plate radius $(r)$ along the reaction surface below the fibers. For better comparability regarding the macroscopic coating uniformity, $R_{\mathrm{W}}$ was normalized by a factor $a_{0}$ towards $100 \mu \mathrm{m} / \mathrm{min}$ at $r=0$. The higher $a_{0}$ is, the longer the deposition process needs to be run to achieve a similar composite thickness.

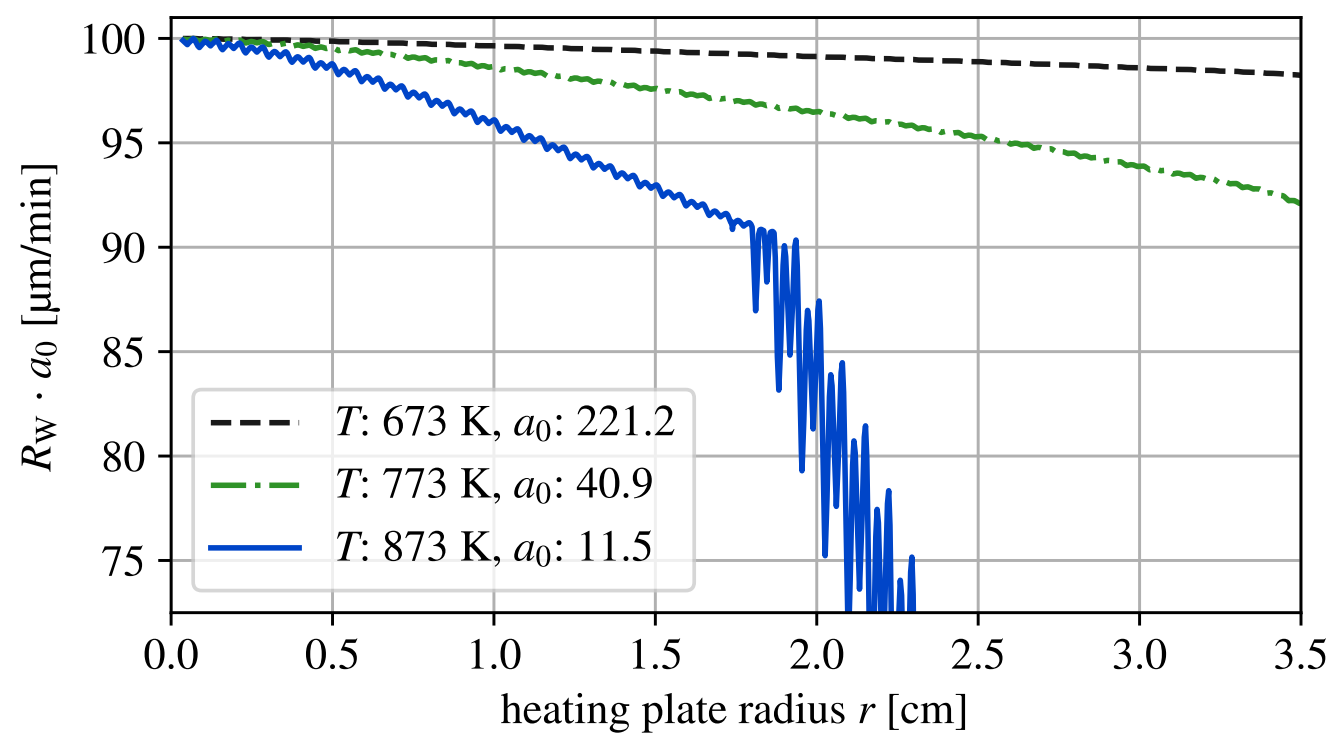

Figure 7. Influence of different $T$ on $R_{\mathrm{W}}$ vs. $r$ along the reaction surface below the fibers (a zoomed section is marked orange in Figure $5 \mathrm{c}) . R_{\mathrm{W}}$ is normalized by a constant $\left(a_{0}\right)$. The other process parameters were $\dot{V}_{\mathrm{WF}_{6}}^{\text {inlet }}=300 \mathrm{sccm}, \dot{V}_{\mathrm{H}_{2}}^{\text {inlet }}=2500 \mathrm{sccm}$, and $P_{\text {tot }}=12 \mathrm{kPa}$. The strongly oscillating parts of the graph are caused by $\mathrm{WF}_{6}$ depletion below the fibers. 
In the same way that a low $T$ is advantageous for a good pore infiltration, a low $T$ also improves the macro-scale coating uniformity from the heating plate's center $(r=0)$ towards the edge $(r=3.5 \mathrm{~cm}$ ), as can be seen in Figure 7 (solid line $\rightarrow$ dash-dotted $\rightarrow$ dashed). The reason for this is again that with a lower $T$, the reaction rate and thus also the precursor consumption decreases exponentially, leading to flatter partial pressure $\left(p_{i}\right)$ gradients.

The substrate geometry (Figure $5 c$ ) leads to different diffusion path-lengths from the pore entrance towards the reaction surface. Therefore, the reaction surface, along which $R_{\mathrm{W}}$ is plotted, received an alternating precursor supply, resulting in an oscillating $R_{\mathrm{W}}$ graph. This becomes especially visible when $T$ becomes so high that $\mathrm{WF}_{6}$ is consumed so fast that there is not enough $\mathrm{WF}_{6}$ for the outer regions of the sample (873 $\mathrm{K}$ (solid line) and $r \geq 1.8$ ). Not enough means that $\mathrm{WF}_{6}$ limits the reaction so that $R_{\mathrm{W}}$ is suddenly reduced significantly as also observed in the micro-scale model. Since this would lead, in the case of the $\mathrm{W}_{f} / \mathrm{W}$ production, to large pores and thus a reduced $\rho_{r e l}$, this should be avoided.

\subsubsection{Variation of $\dot{V}_{\mathrm{WF}_{6}}^{\text {inlet }}$}

The result of varying $\dot{V}_{\mathrm{WF}_{6}}^{\text {inlet }}$ is shown in Figure 8. $T$ was kept at $773 \mathrm{~K}$. As long as there is enough $\mathrm{WF}_{6}$, its influence on the coating uniformity is small. However, if the $\mathrm{WF}_{6}$ supply is set too low, the effect on $R_{\mathrm{W}}$ is the same as for a too high consumption, as discussed for Figure 7, solid line.

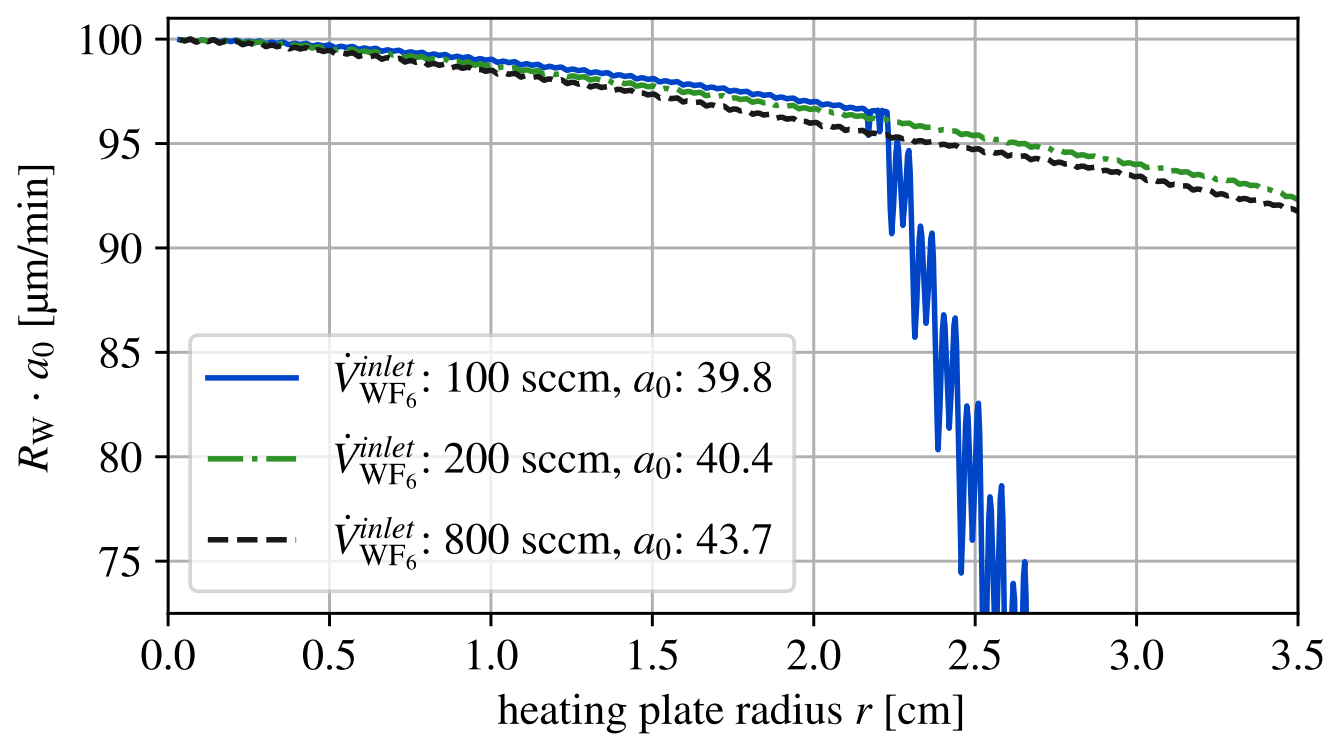

Figure 8. Variation of $\dot{V}_{\mathrm{WF}_{6}}^{\text {inlet }}$ with $T_{\text {Heater }}=773 \mathrm{~K}, \dot{V}_{\mathrm{H}_{2}}^{\text {inlet }}=2500 \mathrm{sccm}, P_{\text {tot }}=12 \mathrm{kPa}$ (otherwise, same caption as in Figure 7).

Keeping $\dot{V}_{\mathrm{WF}_{6}}^{\text {inlet }}$ as low as possible and as high as necessary optimizes the $\mathrm{WF}_{6}$ conversion rate and thus reduces the $\mathrm{WF}_{6}$ demand and cost. A reasonable value also depends on the other process parameters and can be estimated via the reactor model. Further advantages of a lower $\dot{V}_{\mathrm{WF}_{6}}^{\text {inlet }}$ are a slightly improved coating uniformity and a slightly shorter deposition duration needed for a certain coating thickness.

The reason for the improved uniformity is that, with all other process parameters being constant, a reduction in $\dot{V}_{\mathrm{WF}_{6}}^{\text {inlet }}$ leads to a reduced $p_{\mathrm{WF}_{6}}$, which increases the diffusion speed of all species since $\mathrm{WF}_{6}$ is the largest molecule. A faster diffusion flattens the $p_{i}$ gradients. The reason for the shorter duration is that by reducing $\dot{V}_{\mathrm{WF}_{6}}^{\text {inlet }}, p_{\mathrm{H}_{2}}$ is increased, which slightly increases $R_{\mathrm{W}}$ (Equation (4)).

3.2.3. Variation of $\dot{V}_{\mathrm{H}_{2}}^{\text {inlet }}$ and $P_{t o t}$

The variations of $\dot{V}_{\mathrm{H}_{2}}^{\text {inlet }}$ and $P_{\text {tot }}$ are shown in Figures 9 and 10, respectively. 
An improved coating uniformity can be achieved by increasing $\dot{V}_{\mathrm{H}_{2}}^{\text {inlet }}$ and reducing $P_{t o t}$, as both favor diffusion and thus again flatten $p_{i}$ gradients along $r$. A shorter process time can be achieved by increasing both, $\dot{V}_{\mathrm{H}_{2}}^{\text {inlet }}$ and $P_{\text {tot }}$, since both lead to a higher $p_{\mathrm{H}_{2}}$ and thus $R_{\mathrm{W}}$. Therefore, increasing $\dot{V}_{\mathrm{H}_{2}}^{\text {inlet }}$ only has benefits as long as $R_{\mathrm{W}}$ stays independent of $p_{\mathrm{WF}_{6}}$. Furthermore, a higher $\dot{V}_{\mathrm{H}_{2}}^{\text {inlet }}$ rinses away the produced HF more effectively, which lowers $p_{\mathrm{HF}}$ and thus additionally enhances the gas diffusion and thus the coating uniformity at all length scales.

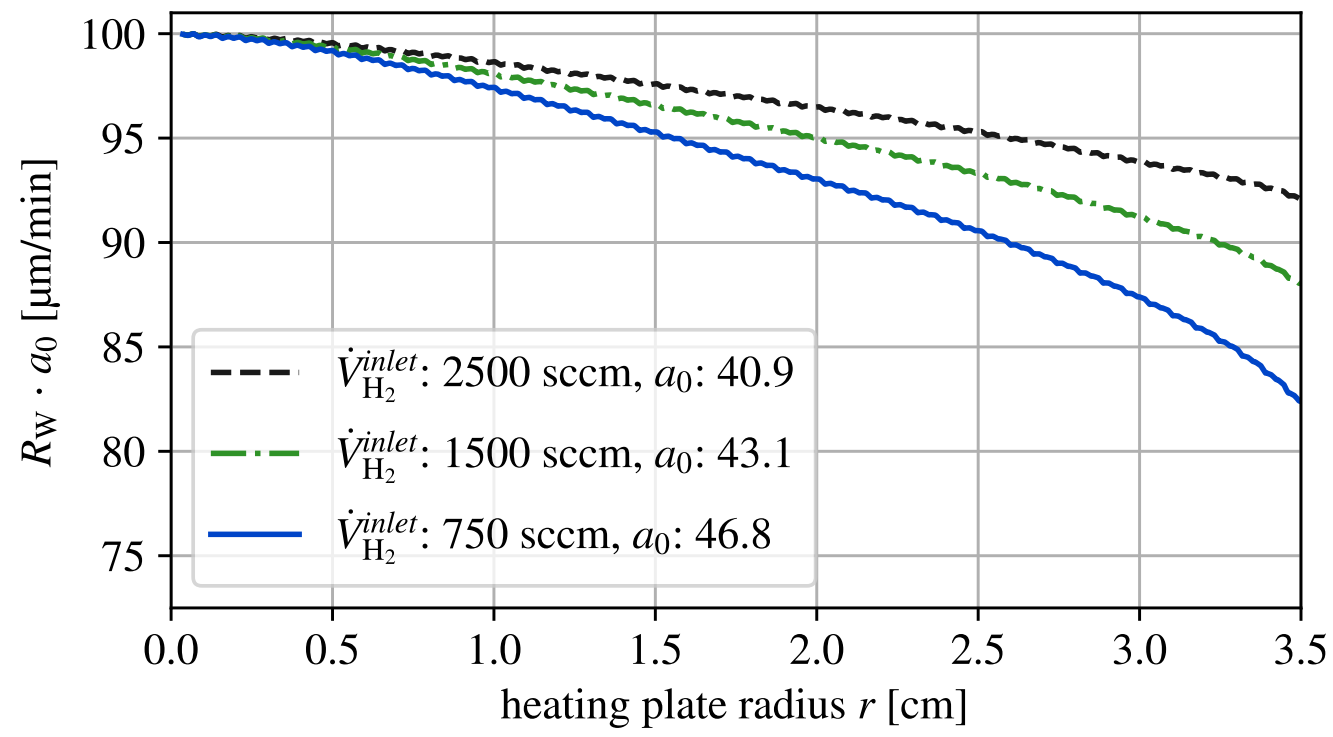

Figure 9. Variation of $\dot{V}_{\mathrm{H}_{2}}^{\text {inlet }}$ with $T=773 \mathrm{~K}, \dot{V}_{\mathrm{WF}_{6}}^{\text {inlet }}=300 \mathrm{sccm}, P_{\text {tot }}=12 \mathrm{kPa}$ (otherwise, same caption as in Figure 7).

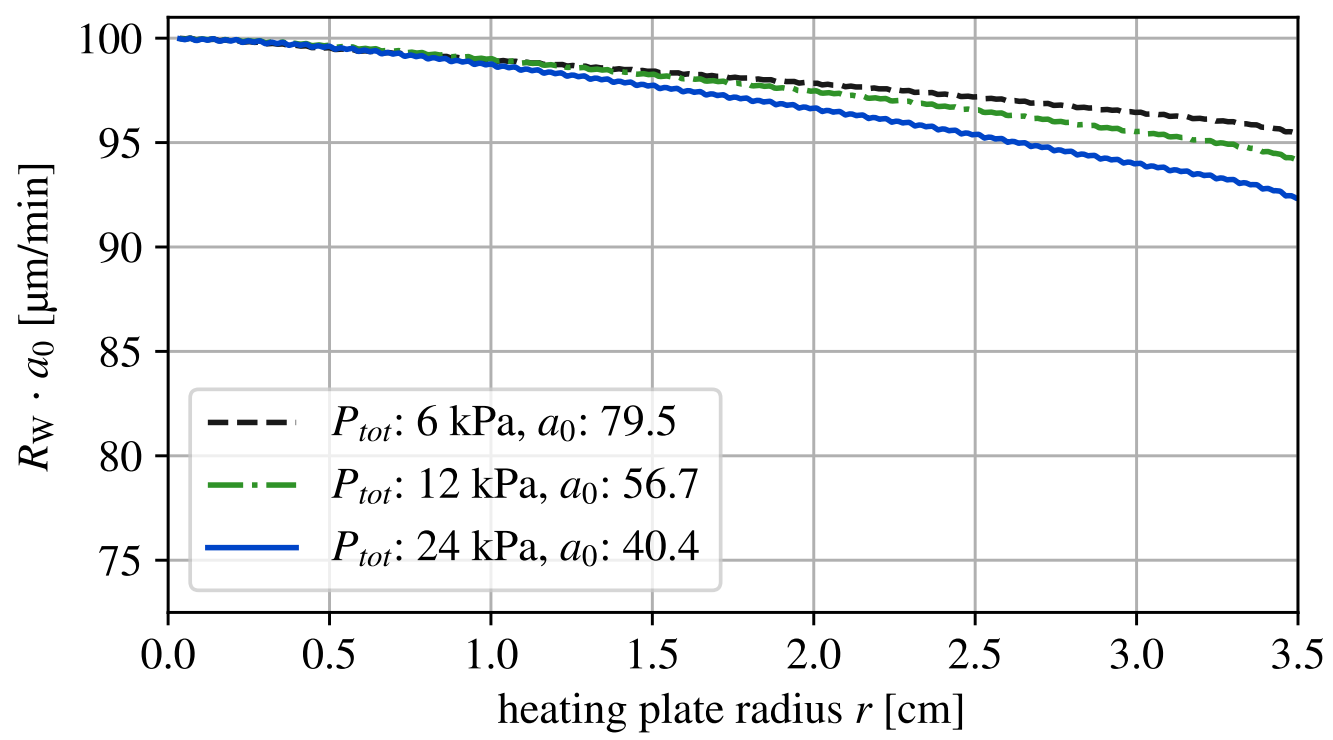

Figure 10. Variation of $P_{\text {tot }}$ with $T_{\text {Heater }}=773 \mathrm{~K}, \dot{V}_{\mathrm{WF}_{6}}^{\text {inlet }}=300 \mathrm{sccm}, \dot{V}_{\mathrm{H}_{2}}^{\text {inlet }}=2500 \mathrm{sccm}$ (otherwise, same caption as in Figure 7).

\subsection{Applying the Improved Parameters}

In Figure 11, the result of applying the improved parameters is shown. As can be seen, there are only few small pores left. Further improvement is only possible if the technological challenges can be overcome to produce more uniform $\mathrm{W}$ fabrics with smaller deviations in fiber spacing and to place these fabrics as closely as possible on top of 
each other. Approaches currently being developed involve the use of filaments woven to yarns [45] and a coiling of the fabric layers under tension [29].

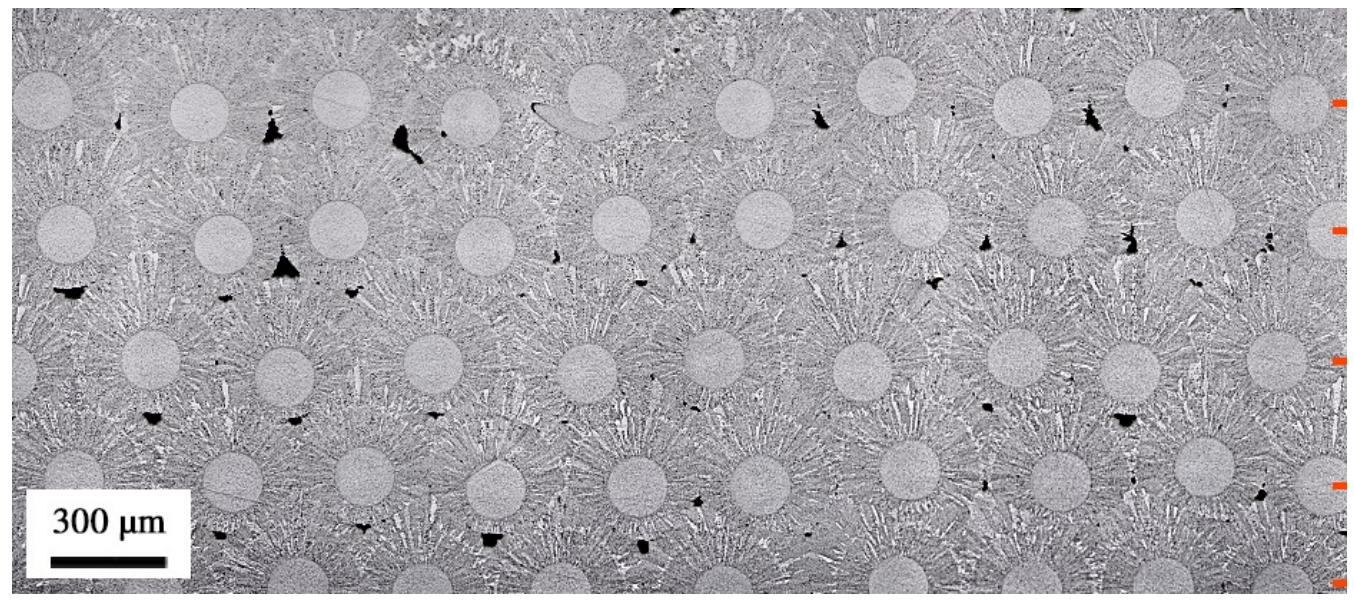

Figure 11. Metallographic polish of an improved $\mathrm{W}_{f} / \mathrm{W}$ sample sliced perpendicularly to the warp fibers. The CVD parameters used were $P_{\text {tot }}=12 \mathrm{kPa}, T_{\text {Heater }}=773 \mathrm{~K}, \dot{V}_{\mathrm{WF}_{6}}^{\text {inlet }}=200 \mathrm{sccm}$, $\dot{V}_{\mathrm{H}_{2}}^{\text {inlet }}=2500 \mathrm{sccm}$. It should be noted that for a different CVD device or other geometries, these parameter values need to be recalculated via the presented model.

\section{Summary and Conclusions}

The goal of the present work was to optimize the CVD process parameters with respect to $\mathrm{W}$ coating uniformity, the $\mathrm{WF}_{6}$ demand and the deposition duration. This was motivated by the fact that for the investigated experimental setup, an increased coating uniformity leads to a higher relative density of the $\mathrm{W}_{f} / \mathrm{W}$ composite, which leads to improved material properties such as higher fracture strength and higher thermal conductivity.

For the present article, COMSOL Multiphysics models (experimentally validated in $[31,36])$ were applied to conduct parameter studies regarding the chemical vapor deposition/infiltration of $\mathrm{W}$ between $\mathrm{W}$ fibers. At the macro scale, the CVD device process parameters (temperature, gas inlet precursor flow rates and total pressure) were varied. At the micro-scale, the precursor partial pressures at the upper model boundary and the temperature were varied. The best parameter set was applied successfully in a new $\mathrm{W}_{f} / \mathrm{W}$ synthesis.

Advantageous CVD process parameter trends, valid also for other geometries and setups, are summarized in Table 1 . The arrows point into the directions in which a process parameter (columns 2 to 4 ) should be set to achieve the criteria (column 1) of the same row.

Table 1. Advantageous CVD process parameter trends regarding certain criteria.

\begin{tabular}{lcccc}
\hline \multirow{2}{*}{ Criteria } & \multicolumn{3}{c}{ CVD Process Parameters (*) } \\
\cline { 2 - 4 } & \multicolumn{1}{c}{$\dot{\boldsymbol{V}}_{\mathbf{W F}_{6}}^{\text {inlet }}$} & $\dot{V}_{\mathbf{H}_{2}}^{\text {inlet }}$ & $\boldsymbol{P}_{\text {tot }}$ \\
\hline low tot. $\mathrm{WF}_{6}$ demand & - & $\downarrow$ & - & - \\
fast process & $\uparrow$ & $(\downarrow)$ & $(\uparrow)$ & $\uparrow$ \\
high $\rho_{\text {rel }}$ and coating uniformity in the micro- and macro-scale & $\downarrow$ & $(\downarrow)$ & $\uparrow$ & $\downarrow$ \\
${ }^{*}$ as long as $R_{\mathrm{W}}$ is not limited by a too low $p_{\mathrm{WF}_{6}}$. & & & &
\end{tabular}

The more uniform the $\mathrm{W}$ coating becomes (macroscopically along the sample and microscopically between the fibers), the faster the precursors can be supplied to the reaction sites and the slower these precursors are consumed there.

A higher $T$ enhances this supply due to faster diffusion [36,41]; however, this is outweighed by an even higher increase in the consumption rate due to the exponentially increase in $R_{\mathrm{W}}$ (Equation (2)). Hence, a higher $T$ makes the process faster but reduces the coating uniformity. The arrows representing the influence on the criteria in Table 1 point in the same direction regarding $P_{t o t}$ and $T$. However, the influence of $P_{t o t}$ is less and 
the reasons for the directions are partly different: $R_{W}$ and the consumption rate increase also with $P_{\text {tot }}$, but not as quickly as with $T$ (due to the $\left[p_{\mathrm{H}_{2}}\right]^{1 / 2}$ term in Equation (4)). Furthermore, a higher $P_{t o t}$ increases the precursor amount near the gas inlet and at the fabric center, but reduces the precursor supply rate towards the ground surface below the fabric and towards the fabric outer edge. The reason for this is a slower diffusion. It should be pointed out that this is only valid if $R_{\mathrm{W}}$ is not limited by $p_{\mathrm{WF}_{6}}$. Otherwise, increasing $P_{\text {tot }}$ can improve the coating uniformity.

Regarding $\dot{V}_{\mathrm{WF}_{6}}^{\text {inlet }}$ and $\dot{V}_{\mathrm{H}_{2}}^{\text {inlet }}$, the criteria uniformity and process time can be improved in parallel, as long as $R_{\mathrm{W}}$ is not limited by a too low $p_{\mathrm{WF}_{6}}$. The reason for this is that by changing the gas inlet flow rates at a constant $P_{t o t}$, the partial pressures are also changed. In addition, if $R_{\mathrm{W}}$ is independent of $p_{\mathrm{WF}_{6}}$, decreasing $\dot{V}_{\mathrm{WF}_{6}}^{\text {inlet }}$ and increasing $\dot{V}_{\mathrm{H}_{2}}^{\text {inlet }}$ improves both the precursor supply (faster diffusion due to smaller $\mathrm{WF}_{6}$ molecules and better rinsing of $\mathrm{HF}$ ) and the process speed (higher $p_{\mathrm{H}_{2}}$ leads to higher $R_{\mathrm{W}}$, Equation (4)).

To conclude, regarding $\mathrm{W}_{f} / \mathrm{W}$ production, advantageous process parameters are a low $T$, resulting in still acceptable process times, a high $\mathrm{H}_{2-}$, and a low $\mathrm{WF}_{6}$-gas flow rate. With the reactor model, one can predict how low the $\mathrm{WF}_{6}$ gas flow may be set, which is dependent on the reactor and substrate geometries and on the other process parameters. It is very important that $R_{\mathrm{W}}$ stays independent of $p_{\mathrm{WF}_{6}}$, since otherwise the micro- and macroscopic coating uniformity as well as the relative density are significantly reduced. If these conditions are fulfilled, a low $P_{t o t}$ gives a small advantage to the coating uniformity. On the other hand, higher values result in a slightly faster process. Therefore, to decide on $P_{t o t}$, more information might be useful: a higher $P_{t o t}$ also leads to a finer CVD-W grain structure ([37], Chapter 6), improving the fracture strengths of the composite matrix (strength vs. grain size for CVD-W: [46], for non-CVD-W: [47,48]; Hall-Petch relation: $[49,50])$. Another advantage of the reactor model for the $\mathrm{W}_{f} / \mathrm{W}$ production is that the needed deposition duration per fabric layer (CVD-substrate) can be estimated well, allowing one to optimize the vertical fabric packing density and thus improve fiber volume fraction and fiber reinforcement [37].

Additionally, for other W-CVD processes, the results should be useful. High $\mathrm{H}_{2-}$ and low $\mathrm{WF}_{6}$-gas flow rates without depleting $\mathrm{WF}_{6}$ should help in every process, whereby at very high $\mathrm{H}_{2}$ flow rates one needs to preheat the gas flow to avoid an inhomogeneous convective cooling of the substrate, which would lead to a more uneven coating again. Depending on which criterion (uniformity, speed, grain size) is important, $T$ and $P_{\text {tot }}$ can be adjusted, as recommended in ([37], Chapter 6) and Table 1.

Author Contributions: L.R.: methodology, investigation, visualization, writing-original draft; J.W.C. \& J.R.: conceptualization, supervision; Y.M.: conceptualization; D.S.: investigation; H.G.: methodology, conceptualization; C.L.: funding acquisition, project administration; O.G.: PhD supervision. All authors contributed additionally with scientific discussions, ongoing feedback and suggestions, and with writing-review and editing. All authors have read and agreed to the published version of the manuscript.

Funding: This work has been carried out within the framework of the EUROfusion Consortium and has received funding from the Euratom research and training programme 2014-2018 and 2019-2020 under grant agreement No 633053. The views and opinions expressed herein do not necessarily reflect those of the European Commission.

Conflicts of Interest: The authors declare no conflict of interest. 


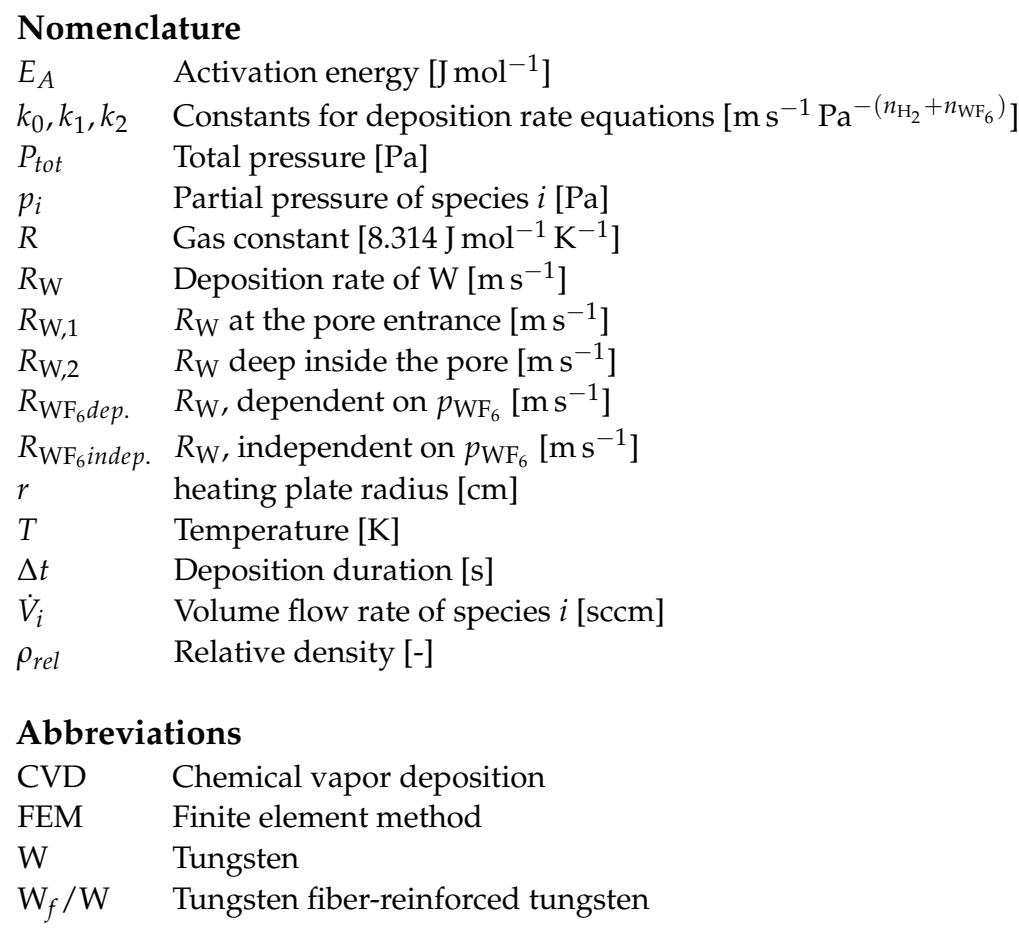

\section{References}

1. Romanelli, F. Fusion Electricity a Roadmap to the Realisation of Fusion Energy; European Fusion Development Agreement, EFDA: Garching, Germany, 2012; ISBN 978-3-00-040720-8.

2. Federici, G.; Giruzzi, G.; Lowry, C.; Kemp, R.; Ward, D.; Wenninger, R.; Zohm, H. EU DEMO design and R\&D studies. In Proceedings of the 2013 IEEE 25th Symposium on Fusion Engineering (SOFE), San Francisco, CA, USA, 10-14 June 2013; pp. 1-8.

3. Zohm, H. Assessment of DEMO challenges in technology and physics. Fusion Eng. Des. 2013, 88, 428-433. [CrossRef]

4. Wenninger, R.; Bernert, M.; Eich, T.; Fable, E.; Federici, G.; Kallenbach, A.; Loarte, A.; Lowry, C.; McDonald, D.; Neu, R.; et al. DEMO divertor limitations during and in between ELMs. Nucl. Fusion 2014, 54, 114003. [CrossRef]

5. Baluc, N. Materials for fusion power reactors. Plasma Phys. Control. Fusion 2006, 48, B165-B177. [CrossRef]

6. Linsmeier, C.; Rieth, M.; Aktaa, J.; Chikada, T.; Hoffmann, A.; Hoffmann, J.; Houben, A.; Kurishita, H.; Jin, X.; Li, M.; et al. Development of advanced high heat flux and plasma-facing materials. Nucl. Fusion 2017, 57, 092007. [CrossRef]

7. Yang, X.; Hassanein, A. Atomic scale calculations of tungsten surface binding energy and beryllium-induced tungsten sputtering. Appl. Surf. Sci. 2014, 293, 187-190. [CrossRef]

8. Jackson, D.P. Binding energies in cubic metal surfaces. Radiat. Eff. 1973, 18, 185-189. [CrossRef]

9. Lassner, E.; Schubert, W.-D. Tungsten-Properties, Chemistry, Technology of the Element, Alloys, and Chemical Compound; Springer: Berlin/Heidelberg, Germany, 1999.

10. Reiser, J.; Rieth, M.; Dafferner, B.; Hoffmann, A. Charpy impact properties of pure tungsten plate material in as-received and recrystallized condition. J. Nucl. Mater. 2013, 442, 204-207. [CrossRef]

11. Bolt, H.; Barabash, V.; Federici, G.; Linke, J.; Loarte, A.; Roth, J.; Sato, K. Plasma facing and high heat flux materials-Needs for ITER and beyond. J. Nucl. Mater. 2002, 307-311, 43-52. [CrossRef]

12. Coenen, J.W.; Antusch, S.; Aumann, M.; Biel, W.; Du, J.; Engels, J.; Heuer, S.; Houben, A.; Höschen, T.; Jasper, B.; et al. Materials for DEMO and reactor applications-Boundary conditions and new concepts. Phys. Scr. 2015, T167, 014002. [CrossRef]

13. Pintsuk, G.; Bobin-Vastra, I.; Constans, S.; Gavila, P.; Rödig, M.; Riccardi, B. Qualification and post-mortem characterization of tungsten mock-ups exposed to cyclic high heat flux loading. Fusion Eng. Des. 2013, 88,1858-1861. [CrossRef]

14. Coenen, J.W. Fusion Materials Development at Forschungszentrum Jülich. Adv. Eng. Mater. 2020, 22, 1901376. [CrossRef]

15. Coenen, J.W.; Mao, Y.; Sistla, S.; Riesch, J.; Höschen, T.; Broeckmann, C.; Neu, R.; Linsmeier, C. Improved pseudo-ductile behavior of powder metallurgical tungsten short fiber-reinforced tungsten $\left(\mathrm{W}_{f} / \mathrm{W}\right)$. Nucl. Mater. Energy 2018, 15, 214-219. [CrossRef]

16. Neu, R.; Riesch, J.; Coenen, J.W.; Brinkmann, J.; Calvo, A.; Elgeti, S.; Garcia-Rosales, C.; Greuner, H.; Höschen, T.; Holzner, G.; et al. Advanced tungsten materials for plasma-facing components of DEMO and fusion power plants. Fusion Eng. Des. 2016, 109-111 Pt A, 1046-1052. [CrossRef]

17. Neu, R.; Riesch, J.; Müller, A.; Balden, M.; Coenen, J.W.; Gietl, H.; Höschen, T.; Li, M.; Wurster, S.; You, J.-H. Tungsten fibre-reinforced composites for advanced plasma facing components. Nucl. Mater. Energy 2016, 12, 1308-1313. [CrossRef]

18. Riesch, J.; Aumann, M.; Coenen, J.W.; Gietl, H.; Holzner, G.; Höschen, T.; Huber, P.; Li, M.; Linsmeier, C.; Neu, R. Chemically deposited tungsten fibre-reinforced tungsten-The way to a mock-up for divertor applications. Nucl. Mater. Energy 2016, 9, 75-83. [CrossRef] 
19. Riesch, J.; Han, Y.; Almanstötter, J.; Coenen, J.W.; Höschen, T.; Jasper, B.; Zhao, P.; Linsmeier, C.; Neu, R. Development of tungsten fibre-reinforced tungsten composites towards their use in DEMO-Potassium doped tungsten wire. Phys. Scr. 2016, T167, 014006. [CrossRef]

20. Gietl, H.; Olbrich, S.; Riesch, J.; Holzner, G.; Höschen, T.; Coenen, J.W.; Neu, R. Estimation of the fracture toughness of tungsten fibre-reinforced tungsten composites. Eng. Fract. Mech. 2020, 232, 107011. [CrossRef]

21. Riesch, J.; Buffiere, J.-Y.; Höschen, T.; di Michiel, M.; Scheel, M.; Linsmeier, C.; You, J.-H. In situ synchrotron tomography estimation of toughening effect by semi-ductile fibre reinforcement in a tungsten-fibre-reinforced tungsten composite system. Acta Mater. 2013, 61, 7060-7071. [CrossRef]

22. Terentyev, D.; Riesch, J.; Lebediev, S.; Khvan, T.; Zinovev, A.; Rasinski, W.; Dubinko, A.; Coenen, J. Plastic deformation of recrystallized tungsten-potassium wires: Constitutive deformation law in the temperature range 22-600C. Int. J. Refract. Met. Hard Mater. 2018, 73, 38-45. [CrossRef]

23. Chawla, K.K. Ceramic Matrix Composites, 2nd ed.; Springer: New York, NY, USA, 2003.

24. Riesch, J. Entwicklung und Charakterisierung Eines Wolframfaserverstärkten Wolfram-Verbundwerkstoffs. Ph.D. Thesis, Technische Universität München, Munich , Germany, 2012.

25. Mao, Y.; Coenen, J.W.; Riesch, J.; Sistla, S.; Almanstötter, J.; Jasper, B.; Terra, A.; Höschen, T.; Gietl, H.; Bram, M.; et al. Development and characterization of powder metallurgically produced discontinuous tungsten fiber reinforced tungsten composites. Phys. Scr. 2017, T170, 014005. [CrossRef]

26. Mao, Y.; Coenen, J.W.; Riesch, J.; Sistla, S.; Almanstötter, J.; Jasper, B.; Terra, A.; Höschen, T.; Gietl, H.; Linsmeier, C.; et al. Influence of the interface strength on the mechanical properties of discontinuous tungsten fiber-reinforced tungsten composites produced by field assisted sintering technology. Compos. Part A Appl. Sci. Manuf. 2018, 107, 342-353. [CrossRef]

27. Coenen, J.W.; Mao, Y.; Sistla, S.; Müller, A.; Pintsuk, G.; Wirtz, M.; Riesch, J.; Höschen, T.; Terra, A.; You, J.-H.; et al. Materials development for new high heat-flux component mock-ups for DEMO. Fusion Eng. Des. 2019, 146, 1431-1436. [CrossRef]

28. Gietl, H.; Müller, A.V.; Coenen, J.W.; Decius, M.; Ewert, D.; Höschen, T.; Huber, P.; Milwich, M.; Riesch, J.; Neu, R. Textile preforms for tungsten fibre-reinforced composites. J. Compos. Mater. 2018, 52, 3875-3884. [CrossRef]

29. Gietl, H.; Riesch, J.; Coenen, J.W.; Höschen, T.; Neu, R. Production of tungsten-fibre reinforced tungsten composites by a novel continuous chemical vapour deposition process. Fusion Eng. Des. 2019, 146, 1426-1430. [CrossRef]

30. Zinn, A.F. The Chemistry of Metal CVD; Chapter: Chemical Vapor Deposition of Tungsten; VCH Verlagsgesellschaft: Weinheim, Germany, 2007; pp. 105-174.

31. Raumann, L.; Coenen, J.W.; Riesch, J.; Mao, Y.; Schwalenberg, D.; Wegener, T.; Gietl, H.; Höschen, T.; Linsmeier, C.; Guillon, O. Modeling and validation of the $\mathrm{W}_{f} / \mathrm{W}$-fabrication by chemical vapor deposition and infiltration. Nucl. Mater. Energy 2021, submit.

32. Gietl, H. Weiterentwicklung von Wolframfaserverstfärktem Wolframverbundwerkstoff für den Einsatz in der Fusion. Ph.D. Thesis, Technische Universität München, Munich, Germany, 2018.

33. Gietl, H.; Riesch, J.; Coenen, J.W.; Höschen, T.; Linsmeier, C.; Neu, R. Tensile deformation behavior of tungsten fibre-reinforced tungsten composite specimens in as-fabricated state. Fusion Eng. Des. 2017, 124, 396-400. [CrossRef]

34. Mao, Y.; Coenen, J.W.; Riesch, J.; Sistla, S.; Almanstötter, J.; Terra, A.; Chen, C.; Wu, Y.; Raumann, L.; Höschen, T.; et al. Fiber Volume Fraction Influence on Randomly Distributed Short Fiber Tungsten Fiber-Reinforced Tungsten Composites. Adv. Eng. Mater. 2020, 22, 1901242. [CrossRef]

35. COMSOL INC. Available online: https://www.comsol.com/(accessed on 6 July 2021).

36. Raumann, L.; Coenen, J.W.; Riesch, J.; Mao, Y.; Gietl, H.; Höschen, T.; Linsmeier, C.; Guillon, O. Modeling and validation of chemical vapor deposition of tungsten for tungsten fiber reinforced tungsten composites. Surf. Coat. Technol. 2020, $381,124745$. [CrossRef]

37. Raumann, L. Modeling and Validation of Chemical Vapor Deposition for Tungsten Fiber Reinforced Tungsten, Volume 515 of Schriften des Forschungszentrums Juelich—Energy and Environment; Forschungszentrum Jülich GmbH: Aachen, Germany, 2020.

38. McInerney, E.J.; Srinivasan, E.; Smith, D.C.; Ramanath, G. Kinetic rate expression for tungsten chemical vapor deposition in different $\mathrm{WF}_{6}$ flow regimes from step coverage measurements. Z. Met. 2000, 91, 573-580.

39. Raumann, GitHub Repository for the Model and Script Files of the Present Work. 2020. Available online: https://github.com/ Leo-Raumann/Dissertation-Files.git (accessed on 6 July 2021).

40. Kuijlaars, K.; Kleijn, C.; van Den Akker, H. A detailed model for low-pressure CVD of tungsten. Thin Solid Film. 1995, 270, 456-461. [CrossRef]

41. Kuijlaars, K.; Kleijn, C.; van Den Akker, H. Multi-component diffusion phenomena in multiple-wafer chemical vapour deposition reactors. Chem. Eng. J. Biochem. Eng. J. 1995, 57, 127-136. [CrossRef]

42. Creighton, J. The surface chemistry and kinetics of tungsten chemical vapor deposition and selectivity loss. Thin Solid Film. 1994, 241, 310-317. [CrossRef]

43. Knudsen, M. The Kinetic Theory of Gases; John Wiley \& Sons, Inc.: New York, NY, USA, 1950.

44. Hasper, A. Modeling and Optimization of the Step Coverage of Tungsten LPCVD in Trenches and Contact Holes. J. Electrochem. Soc. 1991, 138, 1728. [CrossRef]

45. Coenen, J.W.; Treitz, M.; Gietl, H.; Huber, P.; Hoeschen, T.; Raumann, L.; Schwalenberg, D.; Mao, Y.; Riesch, J.; Terra, A.; et al. The use of tungsten yarns in the production for $\mathrm{w} \mathrm{f} / \mathrm{w}$. Phys. Scr. 2020, T171, 014061. [CrossRef] 
46. Subhash, G.; Lee, Y.; Ravichandran, G. Plastic deformation of CVD textured tungsten-I. Constitutive response. Acta Metall. Mater. 1994, 42, 319-330. [CrossRef]

47. Wei, Q.; Jiao, T.; Ramesh, K.T.; Ma, E.; Kecskes, L.J.; Magness, L.; Dowding, R.; Kazykhanov, V.U.; Valiev, R.Z. Mechanical behavior and dynamic failure of high-strength ultrafine grained tungsten under uniaxial compression. Acta Mater. 2005, 54, 7. [CrossRef]

48. Dunstan, D.J.; Bushby, A.J. Grain size dependence of the strength of metals: The Hall-Petch effect does not scale as the inverse square root of grain size. Int. J. Plast. 2014, 53, 56-65. [CrossRef]

49. Hall, E.O. The Deformation and Ageing of Mild Steel: III Discussion of Results. Proc. Phys. Soc. Sect. B 1951, 64, 747-753. [CrossRef]

50. Hansen, N. Hall-Petch relation and boundary strengthening. Scr. Mater. 2004, 51, 801-806. [CrossRef] 